\title{
Influence of Reboxetine on Salivary MHPG Concentration and Cognitive Symptoms Among Patients with Alcohol-Related Korsakoff's Syndrome
}

\author{
T Reuster', J Buechler', P Winiecki' and J Oehler*,' \\ 'Department of Psychiatry and Psychotherapy, University of Technology Dresden, Dresden, Germany
}

\begin{abstract}
This study is based on the hypothesis of a paraventricular cerebral noradrenaline deficit in alcoholic Korsakoff's syndrome. In a randomized open study the effects of a 4-week treatment with the selective noradrenaline reuptake inhibitor reboxetine on (I) the salivary concentration of the noradrenaline metabolite MHPG and (2) changes in cognitive performance measured by the Mini Mental Status Test were examined. The study group consisted of 105 patients diagnosed with alcohol-related Korsakoff's syndrome (ICD- I0: Fl0.6). Korsakoffs patients showed a reduced concentration of salivary MHPG compared to healthy controls; this reduction did not correlate with the results of the Mini Mental Status Test. An increase in salivary MHPG was found together with an improvement in the Mini Mental Status Test both in the verum group treated with reboxetine and in the control group upon completion of the 4-week study. However, a subgroup with a shorter duration of disease $(<1$ year) was found to profit significantly from reboxetine treatment, as shown by improvements in cognitive performance.

Neuropsychopharmacology (2003) 28, 974-978, advance online publication, 26 March 2003; doi: I 0. I038/sj.npp. I 300 I I 8
\end{abstract}

Keywords: alcoholic Korsakoff's psychosis; salivary MHPG; selective noradrenaline reuptake inhibitor; Mini Mental Status Test

\section{INTRODUCTION}

The alcohol-conditioned amnestic syndrome (ICD-10: F 10.6), also known as Korsakoffs psychosis, is not considered as merely a cerebral nutritional disorder related to thiamine deficiency; it is also thought to be an expression of a local noradrenaline deficit occurring as a result of a substanceinduced damage to neuronal projections (Mrazek et al, 1999; Poeck, 1998; Pfeiffer, 1985; Preuß and Soyka, 1997; Thier, 1993). The function of cognitive tasks such as memory, learning and selective attentiveness is regulated in the prefrontal cortex and the locus coeruleus in particular by ascending pathways of the noradrenergic nervous system (Coull, 1994). Participation of the serotonergic system has been reported on in great detail, as it has a beneficial effect of fluvoxamine on memory disturbances, albeit in a very small sample of patients (Stapleton et al, 1988; Martin et al, 1995).

Neuropathological atrophic modifications have been found in the mamillary body, the aqueduct, subependymal structures of the 3rd and 4th ventricle, and parts of the hypothalamus and thalamus (Butters and Granholm, 1984;

\footnotetext{
* Correspondence: Dr T Reuster, Klinik für Psychiatrie und Psychotherapie, Universitätsklinikum Dresden, Fetscherstr. 74, 0I307 Dresden, Germany, Tel: +49 35। 458 3536, Fax: +49 35। 458 588I, E-mail: thomas.reuster@mailbox.tu-dresden.de

Received 04 June 2002; revised 30 October 2002; accepted 07 November 2002

Online publication: 22 November 2002 at http://www.acnp.org/ Citations/Npp I 12202434
}

Pfeiffer, 1985; McEntee and Mair, 1984). Significant improvements in memory function were found by McEntee and Mair $(1980$ and Mc Entee et al $(1981,1987))$ in patients with Korsakoff's syndrome following treatment with the $\alpha-2$ receptor agonist clonidine; improvements in memory were correlated with an increase in CSF MHPG levels. Memory improvements were also shown among Korsakoff's patients treated with 3,4dihydroxyphenylserine (DOPS), a nonphysiological noradrenaline precursor, in a double-blind study performed by Langlais et al (1987).

On the basis of these findings, the aim of this study was to investigate whether the centrally selective noradrenaline reuptake inhibitor reboxitine leads also to clinically perceptible improvements in cognitive deficits and to modifications in the MHPG concentration. An effective and practical therapy for (chronic) Korsakoff's syndrome is not yet known, and treatments employed in clinical practice have been highly inconsistent according to our own experience and communications published in the literature (Preuß and Soyka, 1997).

\section{MATERIALS AND METHODS}

\section{Subjects}

A total of 105 patients with Korsakoff's syndrome from 14 clinics and/or nursing homes (all the previously mentioned studies worked with considerably smaller patient numbers) could be included in the study. 
The patients had to fulfil the following inclusion criteria:

- clinically certain diagnosis according to ICD 10 (F 10.6),

- voluntary participation after informed consent, if necessary consent from a guardian,

- age between 18 and 69 years,

- no complicating diseases,

- no additional psychiatric diagnosis, particularly depression,

- no pregnancy,

- constant medical care,

- no simultaneous antidepressant medication.

Of the examined patients, $23.8 \%$ were women and $76.2 \%$ were men. The average age of all patients was 49.8 years, of which the women were 48.6 years and the men 51.1 years of age on average. Results were evaluated considering the independent variables sex, age, duration of disease before study onset, and severity of disease at study onset.

For the most part, the patients in the nursing homes had already been diagnosed with Korsakoff's syndrome several years previously; all had suffered for at least 1 year. The duration of disease before study onset was considerably shorter among the hospital patients, that is, between 3 weeks and at most 1 year (mean of 3 months).

Patients of the verum and control groups were matched with respect to the following variables:

(a) male/female,

(b) test results in the Mini Mental Status Test $<19$ points or $\geqslant 19$ points, ${ }^{1}$

(c) time after diagnosis $<6$ weeks/ $>6$ weeks.

\section{Drug Administration and Investigation Procedure}

The patients of the verum group received $8 \mathrm{mg}$ reboxetine daily $(2 \times 4 \mathrm{mg}$ doses $)$ over 4 weeks per os. Those of the control group received no reboxetine; six male patients (three each in the verum and control groups) also received between 50 and $300 \mathrm{mg}$ parenteral thiamine daily following a previous programme of medication. Moreover, no other psychoactive drugs (antidepressants, neuroleptics, sedatives, and hypnotics) were administered in both groups. No patient consumed any alcohol when they were receiving treatment. Psychological dehabilitation therapy was not undertaken during the experimental period because of the mental status of the patients. The measuring time points were days 0 and 28. On these days, the patients underwent a Mini Mental Status Test for reliably measuring cognitive functions (Folstein et al, 1975). In deciding for the relatively unspecific, but simple MMST, compliance rather than theoretic aspects was instrumental. The examiner was always the same. A saliva sample was also taken from each patient at both measuring points; the sample was deep frozen at $-70^{\circ} \mathrm{C}$ within $6 \mathrm{~h}$.

For the indirect determination of cerebral noradrenaline, the concentration of its metabolite MHPG was measured. We refrained from performing a lumbar puncture on most

\footnotetext{
${ }^{1}$ This value was reported as the representative average of the Mini Mental Status Test from 19 Korsakoff patients in an unpublished study (Reuster and Buntrock, 1999).
}

of the patients in our care for ethical and legal reasons, but in another study we were able to show that a highly significant correlation exists between MHPG in saliva and the CSF ( $r=0.76, p<0.001, n=21$ ) (Reuster et al, 2002). For this reason, we determined MHPG from a small salivary sample, which was obtained using a Sarstedt Salivette ${ }^{\circledR}$.

Measurement of salivary MHPG concentration was performed using a procedure modified from that of Ko et al (1997); this involved sample purification using a solidphase extraction followed by separation on HPLC and electrochemical detection.

\section{Statistics}

For multivariate testing of the influence of the factors sex, duration of illness, reboxetine, and the covariable age, a general repeated measurement model was calculated using the SPSS statistical programme. Since the sizes of the samples for this model were sometimes relatively small (57 sample pairs could be evaluated for the MHPG measurement), univariate analyses were also performed using variance analysis, $t$-tests, Mann-Whitney $U$-tests, and Wilcoxon tests. Results were deemed significant at $p<0.05$ for a two-tailed test. The connection between MHPG and MMST was calculated using Spearman's rank correlation.

\section{RESULTS}

The most important results are presented in Figures 1 and 2. Of the 105 cases, 98 could be evaluated in full by the mini mental test ( 23 female, 75 male). A total of 57 value pairs could be employed for evaluating changes in the MHPG concentration, and four patients had to terminate their participation because of side effects, particularly excessive unrest. Several samples could not be analyzed because of technical problems encountered in the laboratory.

\section{MHPG}

The completely evaluated cases revealed in the univariate analysis a significant reduction of initial MHPG concentration in the saliva of patients with Korsakoff's syndrome in comparison with healthy controls $\left(t_{41}=2.023, p=0.050\right)$. Patient gender exerted no significant influence but women showed a higher MHPG mean value as a starting value and a weaker increase in MHPG at the end of the study compared to men (Figure 1). A reference value for salivary MHPG was formed from a random sample of 21 healthy probands (employees from our unit, 10 female, 11 male, average age 42.6 years) and was found to be $12.85 \mathrm{ng} / \mathrm{ml}$ (range 1.4632.13, SD 9.25). Detection of MHPG was performed by the same laboratory.

The multivariate analysis revealed that a significant difference between the first and the second measurement was evident $\left(F_{1,48}=5.32, p=0.025\right)$. This was found to be dependent only on age: The younger the patient, the more marked was the increase $\left(\mathrm{F}_{1,48}=4.49, p=0.039\right)$.

\section{MMST}

In the univariate calculation, the results in the Mini Mental Status Test at the end of the 4-week study did not reveal any 


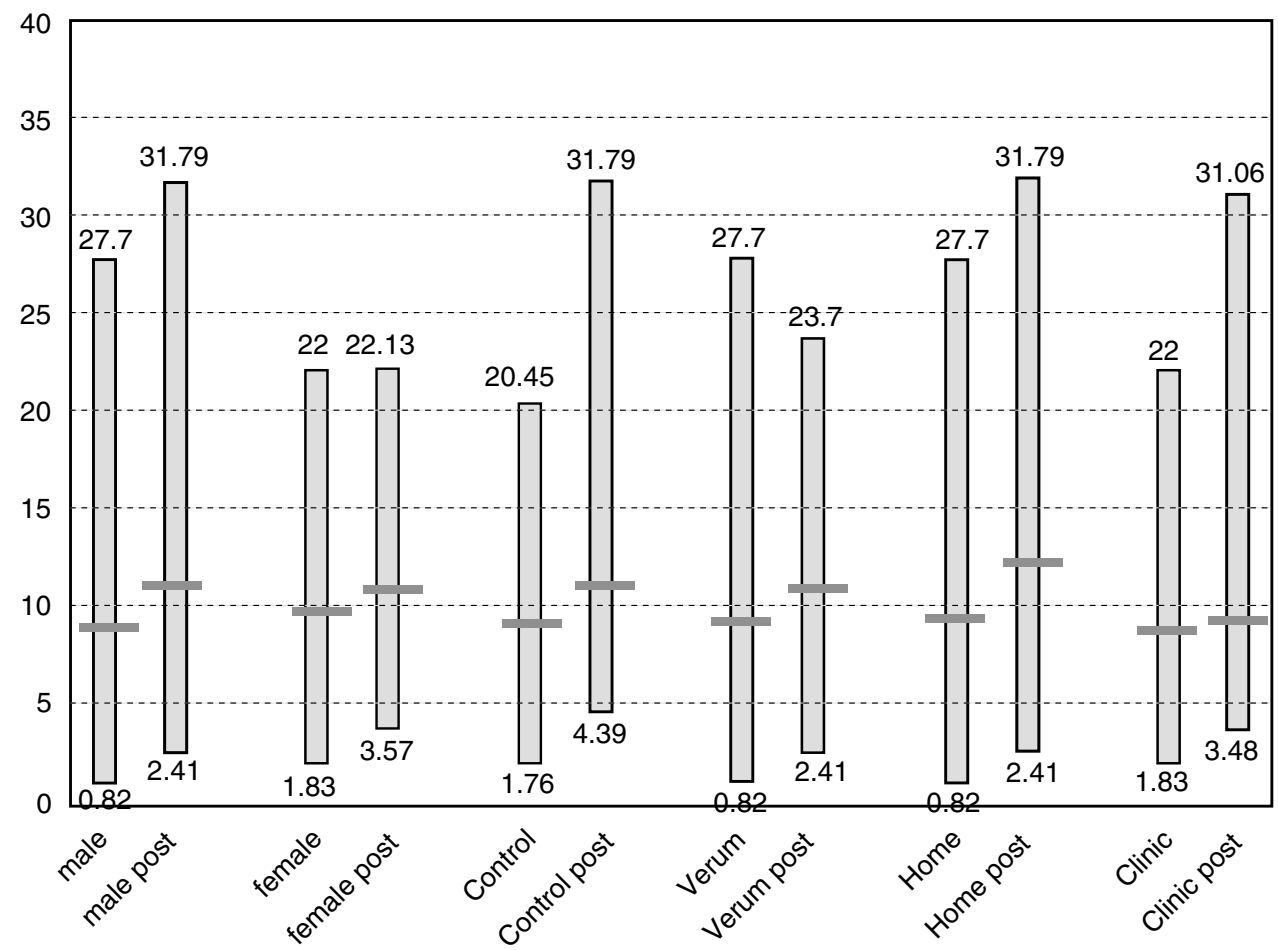

Figure I Minimum, maximum, and mean values of MHPG in saliva among the groups.

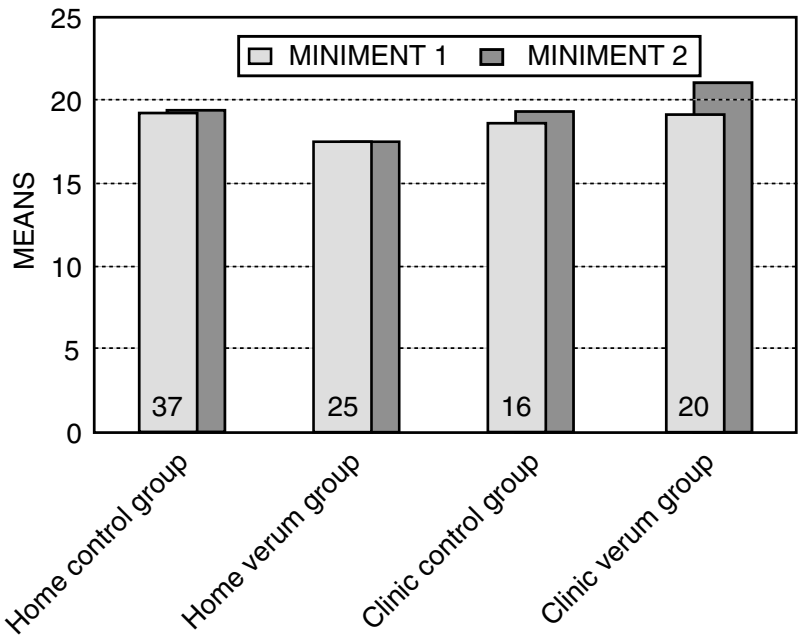

Figure 2 Comparison of MMST control and verum in the subgroups nursing home and hospital.

relevant differences between the verum and control groups $\left(t_{82}=0.78 ; p=0.437\right)$. However, when comparing the subgroups of 'nursing home patients' with a chronic syndrome and 'hospital patients' with a relatively shortexisting syndrome (maximum of 1 year, 3 months on average), nursing home patients revealed lower initial and final values than the hospital patients (Figure 2).

Among patients with a shorter duration of disease (hospital patients) a group difference was apparent to the benefit of the treatment group; in this group, reboxetine dosing was correlated with a significantly better clinical outcome $\left(t_{19}=2.26, p=0.036\right)$ as shown in Figure 2 .
However, the clinic control group also showed (nonsignificantly) improved values.

The multivariate analysis also revealed two significant interactions: (1) The increase in the MMST score was stronger in all patients with a short duration of illness (hospital) than it was in patients who suffered more chronically (domiciled) $\left(\mathrm{F}_{1,89}=8.85, p=0.004\right)$. (2) among women (23.5\% of the sample), MMST values also increased in the clinic, but among the domiciled women it decreased $\left(\mathrm{F}_{1,89}=7.31, p=0.008\right)$. Accordingly, gender correlated with the increase in the MMST score.

Overall, patients with a shorter duration of disease, and who were treated in hospital with reboxetine, showed a significant improvement in cognitive symptoms and this effect appeared to be more marked among women. It should also be pointed out that when certain memory-related items of the MMST are selected on their own, no significant deviations from the global test results can be found.

\section{Correlation Between MHPG and Cognitive Performance}

As expected, our patients revealed a reduction of the MHPG baseline, which both in the therapy and control groups increased by about the same amount $(2.93$ and $1.95 \mathrm{ng} / \mathrm{ml}$ compared to the mean, respectively). In both groups, MHPG values did not correlate with MMST scores either at the beginning or at the end of the study $(p=0.39$, $r=0.096 ; p=0.49, r=0.088$, respectively).

\section{DISCUSSION}

The hypothesis stating that an indirect noradrenergic stimulation of damaged neuronal projections results in a 
functional improvement of cognitive and mnestic performance among patients with an alcohol-toxic Korsakoff's syndrome is partially supported by our study that involved a 4-week treatment with the selective noradrenaline reuptake inhibitor reboxetine.

A significant improvement in cognition was found in hospital patients treated with reboxetine who had only suffered a short duration of about 3 months on average. A slight improvement was documented for the hospital patients control group, whereas no difference was found for patients (verum and control) with a longer disease duration. In contrast, the patients with a chronic disease process who were already living in nursing homes revealed no improvements neither with nor without reboxetine treatment (Figure 2).

These results conflict with the findings of McEntee and Mair (1978, 1980, 1981), and Mair and McEntee (1983), who in their Korsakoffs patients found memory deficits correlating with CSF-MHPG values. These deficits significantly improved in response to clonidine $(n=8)$ in line with simultaneously increasing CSF MHPG values. However, O'Carroll et al (1993) as well as Moffoot et al (1994) were not able to replicate these findings.

Since in our study all hospital patients (with a shorter duration of disease) improved in the MMST, this allows us to conclude that the effect was due either to the efficacy of the hospital setting, a better spontaneous prognosis for early cases (Victor and Laurenco, 1978; Marneros, 1980), or a combination of both factors. However, since only the verum group achieved a significant increase in the MMST scores, an additional positive influence of the medication also seems highly probable.

It is also worthy of note that treatment with the selective noradrenaline reuptake inhibitor reboxetine is not reflected by a change in salivary MHPG content; one would normally expect an increase in centrally available noradrenaline in the synaptic cleft following such treatment.

However, regarding reboxetine, no appropriate studies have as yet been performed in man. Concerning alterations in MHPG, there was no correlation with reboxetine dosing, and regarding McEntees and Mairs' $(1978,1980,1981)$, and Mair and McEntee (1983) findings there was also no correlation with the results of the Mini Mental Status Test. Measurement of MHPG in the saliva after 4 weeks revealed a nonsignificant rise in both groups, which was much more marked in the control group (Figure 1). We could not therefore determine an influence of the 4-week reboxetine treatment on MHPG concentration.

However, in our sample we also found lowered initial MHPG values, an observation consistent with the earlier findings of others (McEntee and Mair, 1978, 1984; McEntee et al, 1987). Nevertheless, our MHPG values did not correlate intraindividually with the initial MMST score and did not climb during the course of treatment in either group, irrespective of the increasing MMST score. This finding is in stark contrast to that of McEntee and Mair, and supports the contradiction published by Martin et al (1984, 1995).

It should be noted that measuring MHPG in saliva includes sources of MHPG produced centrally, peripherally, and locally (Schwab et al, 1992). Even with an overall highly significant relation between CSF and salivary MHPG, quantitative assessments must be related to central noradrenaline turnover on an individual basis. However, with this reservation, the method did appear to be adequately reliable to us as a semiquantitative procedure and with sample sizes $>20$ (Reuster et al, 2002). Our results allow us to conclude that among patients with a still relatively recent onset of Korsakoff's syndrome, reboxetine dosing can contribute to improvements in cognitive performance. These results seem inconsistent with the antidepressive effects of medications on an accompanying depression, since we only included patients without any clinically evident depression according to ICD-10. However, in future studies, subclinical antidepressive effects should be controlled by objective tests. In order to check the reboxetine effect, one should focus especially on patients with a short duration of illness, and the patients should be differentiated according to the extent of cognitive-mnestic defects. Although the role of the noradrenergic system in cognitive defects within alcohol-related Korsakoff's syndrome needs to be described better, this therapeutic option may provide an alternative or supplement to fluvoxamine application. Adequate knowledge of the differential pathophysiology that might justify rational therapeutic differential indications still remains to be acquired.

\section{REFERENCES}

Butters N, Granholm E (1984). The continuity hypothesis: alcoholic Korsakoff's Syndrome. In: Butters N, Wolfe J, Martone M, Granholm E, Cermak LS (eds). Neurobiology of learning and memory. New York: Guilford Press. pp 176-206.

Coull JT (1994). Pharmacological manipulations of the $\alpha 2$ noradrenergic system, effects on cognition. Drugs Aging 5: $116-126$

Folstein MF, Folstein SE, McHugh PR (1975). Mini-Mental-State. A practical method for grading the cognitive state of patients for the clinician. J Psychiatr Res 12: 189-98.

Ko HC, Lu RB, Shiah IS, Hwang CC (1997). Plasma free 3-methoxy4-hydroxyphenylglycol predicts response to fluoxetine. Biol Psychiatry 41: 774-781.

Langlais PJ, Mair RG, Anderson CD, McEntee WJ (1987). Monoamines and metabolites in cortex and subcortical structures: normal regional distribution and the effects of thiamine deficiency in the rat. Brain Res 42: 140-149.

Mair RG, McEntee WJ (1983). Korsakoff's psychosis: noradrenergic systems and cognitive impairment. Behav Brain Res 9: 1-32.

Marneros A (1980). Alkoholisches Korsakow-Syndrom. Act Neurol 7: 87-94.

Martin PR, Adinoff B, Lane E, Stapleton JM, Bone GA, Weingartner $\mathrm{H}$ et al (1995). Fluvoxamine treatment of alcoholic amnestic disorder. Eur Neuropsychopharmacol 5: 27-33.

Martin PR, Weingartner H, Gordon EK, Burns RS, Linnoila M, Kopin IJ et al (1984). Central nervous system catecholamine metabolism in Korsakoff's psychosis. Ann Neurol 15: 184-191.

McEntee WJ, Mair RG (1978). Memory impaiment im Korsakoff's psychosis: a correlation with brain noradrenergic activity. Science 202: 905-907.

McEntee WJ, Mair RG (1980). Memory enhancement in Korsakoff's psychosis by clonidine: further evidence for a noradrenergic deficit. Ann Neurol 5: 466-470.

McEntee WJ, Mair RG (1984). Neurochemical pathology in Korsakoffs psychosis: implications for other cognitive disorders. Neurology 34: 648-652. 
McEntee WJ, Mair RG, Langlais PJ (1981). Clonidine in Korsakoff's disease: pathophysiologic and therapeutic implications. Prog Clin Biol Res 71: 211-223.

McEntee WJ, Mair RG, Langlais P (1987). Neurochemical specificity of learning: dopamine and motor learning. Yale $J$ Biol Med 60: 187-193.

Moffoot A, O'Carroll RE, Murray L, Dougall N, Ebmeier K, Goodwin GM (1994). Clonidine infusion increases uptake of $99 \mathrm{mTc}$-exametazime in anterior cingulate cortex in Korsakoff's psychosis. Psychol Med 24: 53-61.

Mrazek M, Menges C, Steffes J, Thelen B, Erkwoh R (1999). Therapeutische Erfahrungen beim alkoholbedingten KorsakowSyndrom. Nervenarzt 70: 790-794.

O'Carroll RE, Moffoot A, Ebmaier KP, Murray C, Goodwin GM (1993). Korsakoff's syndrome, cognition and clonidine. Psychol Med 23: 341-347.

Pfeiffer J (1985). Atrophic processes in the brain of chronic alcoholics. Nervenarzt 56: 649-657.

Poeck K (1998). Neurologie, 8th edn. Springer: Berlin, Heidelberg, New York.
Preuß UW, Soyka M (1997). Das Wernicke-Korsakow-Syndrom: Klinik, Pathophysiologie und therapeutische Ansätze. Fortschr Neurol Psychiatry 65: 413-420.

Reuster T, Rilke O, Oehler J (2002). High correlation between salivary MHPG and CSF MHPG. Psychopharmacology 162: 415-418.

Schwab KO, Heubel G, Bartels H (1992). Free epinephrine, norepinephrine and dopamine in saliva and plasma of healthy adults. Eur J Clin Chem Biochem 30: 541-544.

Stapleton JM, Eckardt MJ, Martin P, Adinoff B, Roehrich L, Bone G et al (1988). Treatment of alcoholic organic brain syndrome with the serotonin reuptake inhibitor fluvoxamine: a preliminary study. Adv Alcohol Subst Abuse 7: 47-51.

Thier P (1993). Alkoholfolgekrankheiten. In: Brandt T, Dichgans J, Diener H-C (eds). Therapie und Verlauf Neurologischer Erkrankungen. Stuttgart Berlin Köln, W. Kohlhammer. pp 841-863.

Victor M, Laurenco R (1978). Neurologic complications of alcohol abuse: epidemiologic aspects. Adv Neurol 19: 603-617. 